\title{
Design Pedagógico: um olhar na construção de materiais educacionais digitais ${ }^{1}$
}

\author{
Cristina Alba Wildt Torrezzan \\ Orientadora: Prof. ${ }^{a}$ Dr. ${ }^{a}$ Patricia Alejandra Behar \\ Resenha de Dissertação \\ Programa de Pós-Graduação em Informática na Educação \\ Universidade Federal do Rio Grande do Sul (UFRGS) \\ Caixa Postal 5071 - 90.041-970 - Porto Alegre - RS - Brasil \\ crisawt@gmail.com, pbehar@terra.com.br
}

\begin{abstract}
Resumo: O presente estudo tem como objetivo a elaboração de parâmetros, baseados no design pedagógico, para a construção de materiais educacionais digitais (MED's). Esse tema justifica-se na necessidade desses materiais serem elaborados a partir do concomitante planejamento técnico, gráfico e pedagógico. Para o desenvolvimento desta dissertação, primeiramente realizou-se uma pesquisa bibliográfica sobre os principais fatores técnicos, gráficos e pedagógicos envolvidos na elaboração de materiais digitais. Após, desenvolveu-se a conceituação e as metas do design pedagógico, empregando-as na construção do objeto de aprendizagem (OA) PEDESIGN. A partir da aplicação do referido $\mathrm{OA}$ em dois cursos, foram coletados dados que, após analisados e discutidos, originaram como resultado uma tabela de parâmetros para a construção de materiais educacionais digitais baseados no design pedagógico. A partir da proposição desses parâmetros, objetiva-se incentivar a reflexão de professores, pedagogos, designers e desenvolvedores de materiais educacionais digitais sobre a aplicação do design pedagógico em MED's.
\end{abstract}

Palavras-Chave: Educação a distância, materiais educacionais digitais, design de interface, relação homem-máquina, design pedagógico, aprendizagem.

\section{Pedagogic Design: a look into the development of digital educational materials}

Abstract: The present paper aims at generating pedagogic-design-based parameters for the developing of digital educational materials (DEMs). This theme lays on the necessity of developing these materials according to a technical, graphical and pedagogic planning. Primarily, in order to develop this dissertation, a bibliographic research on the main technical, graphic and pedagogic factors involved in the elaboration of digital materials was accomplished. After that, the conceptualization and the objectives of pedagogic design were developed to be used in the elaboration of PEDESIGN learning object (LO). Through the application of the referred LO in two courses, it was accomplished the collection of data which were analyzed and discussed and later originated a table of parameters for the elaboration of pedagogic-design-based digital educational materials. The proposal of such parameters aims at motivating the reflection of teachers, pedagogues, designers and digital educational materials developers on the application of pedagogic design in DEMs.

Keywords: Distance education, digital educational materials, interface design, human-computer relationship, pedagogic design, learning process.

\section{Resenha}

\footnotetext{
${ }^{1}$ Dissertação (Mestrado) - Universidade Federal do Rio Grande do Sul. Faculdade de Educação. Programa de Pós-Graduação na Educação, 2009, Porto Alegre, BR-RS. Orientadora: Prof. ${ }^{a}$ Dr. ${ }^{a}$ Patricia Alejandra Behar.
} 
Frente à expansão da internet e das tecnologias digitais em várias áreas da sociedade atual, verifica-se a crescente aplicação de recursos digitais na educação. Porém, a maioria desses materiais educacionais digitais (MED's) é desenvolvida a partir da simples digitalização de materiais educacionais analógicos. Além disso, normalmente ocorre um desequilíbrio entre fatores técnicos, gráficos e pedagógicos nos MED's. No caso do MED ser elaborado por professores da informática, por exemplo, o planejamento dos fatores técnicos irá prevalecer sobre os demais. No caso de ser construído por professores oriundos do Curso de Pedagogia, será dedicada maior atenção aos fatores pedagógicos. Porém, a simples digitalização subestima o potencial das tecnologias digitais, limitando as estratégias de ação possibilitadas ao usuário. A desigualdade entre os fatores técnicos, gráficos e pedagógicos, por sua vez, prejudica a ação do usuário sobre o MED. Essas situações ocorrem no momento em que se tenta utilizar a metodologia tradicional de ensino na aplicação das tecnologias digitais na educação. Torna-se necessário refletir sobre novos métodos de construção de MED's, que ultrapassem os paradigmas da educação tradicional, sob pena de não apoiar o novo perfil do aluno da geração digital. Desse modo, esta pesquisa organiza, conceitua e relaciona os principais fatores técnicos, gráficos e pedagógicos envolvidos na construção de MED's. O objetivo é gerar uma reflexão sobre a importância da aplicação do design pedagógico, assim como investigar os parâmetros de construção responsáveis pela construção de materiais educacionais digitais sob o ponto de vista do design pedagógico.

O desenvolvimento desta pesquisa ocorreu em três etapas. Na primeira etapa foi realizado um estudo a respeito dos fatores técnicos (interface homem-máquina, usabilidade, acessibilidade, navegação, interação e interatividade); gráficos (design, estética e teoria semiótica) e pedagógicos (construtivismo de Piaget e a aplicação das tecnologias digitais na educação) mais utilizados na elaboração de materiais digitais. Após, relacionou-se esses fatores ao uso educacional, através da proposição do conceito e das metas do design pedagógico.

A escolha do termo design pedagógico justifica-se na intenção do próprio nome explicitar a união de diferentes fatores. Portanto, DP=design+pedagogia, ou seja, referese a integração entre o planejamento pedagógico, programação informática e desenho de interface. Ressalta-se ainda a diferença entre a nova proposta do design pedagógico e o design instrucional. Considera-se que eles não sejam sinônimos. Na realidade entende-se que o design instrucional seja uma das competências do design pedagógico. Para melhor entendimento torna-se relevante citar Romiszowski e Romiszowski (2009): “(...) não há muita literatura original sobre o design instrucional de objetos de aprendizagem. (...) o que falta é uma bibliografia paralela sobre outras fases de planejamento e gestão de grandes projetos de inovação educacional". Portanto, o design pedagógico atua na proposição de um novo planejamento de MED's, por sua vez baseado numa metodologia que ultrapassa os limites da educação tradicional. Relaciona-se com a administração de distintas áreas de estudo. Por isso o design pedagógico pode ser ainda definido como a união dos tipos de design instrucional, educacional, didático e de sistema. Ele não somente elabora interfaces interativas como organiza e relaciona diferentes mídias com conteúdos, práticas pedagógicas, o sistema informático utilizado e a postura ativa do aluno. $\mathrm{O}$ estado da arte do design pedagógico está justamente na gestão dessas áreas de estudo durante a fase de planejamento, na tentativa de construir um material educacional digital que possibilite ao usuário uma postura autônoma, motivadora, crítica, divertida, interativa, desafiadora, instigante, impressionante e colaborativa. Enquanto os tipos de design citados possuem como foco o produto a ser gerado, o DP foca a ação do usuário 
sobre o produto. A intenção é contribuir para a discussão sobre o desenvolvimento de MED's que apóiem a aplicação das tecnologias digitais na educação e colaborem para a elaboração de uma nova concepção de ensino para além dos limites da educação tradicional. Sob essa perspectiva elaborou-se as metas $^{2}$ do design pedagógico, ou seja, pontos a serem contemplados durante o concomitante planejamento técnico-gráficopedagógico de MED's:

A) A utilização da imagem sob o ponto de vista do design pedagógico

B) Aplicação do caráter icônico da imagem na ergonomia do MED

C) Construção do conhecimento através da experiência estética

D) Proposição de um planejamento técnico de apoio à trajetória do usuário

Na segunda etapa as metas do design pedagógico foram aplicadas na construção de um MED, na forma de objeto de aprendizagem. O seu planejamento e execução foram baseados na metodologia de Amante e Morgado (2001) e implementados juntamente com a equipe do NUTED/UFRGS. O objeto de aprendizagem, voltado a educadores, designers, programadores e demais elaboradores de MED's, aborda questões a respeito da construção do design pedagógico, com o objetivo de propor uma reflexão a respeito da importância do design pedagógico na construção de materiais educacionais digitais. Por isso foi denominado PEDESIGN (design pedagógico). Pode ser aplicado em aulas presenciais ou virtuais (neste caso deverá ser apoiado por um ambiente virtual de aprendizagem). Encontra-se disponível no endereço http://www.nuted.edu.ufrgs.br/pedesign

Aplicando as metas do DP, o Objeto de aprendizagem PEDESIGN propõe a contemplação de uma navegação predominantemente não-linear, possibilitando uma exploração com liberdade. Para tanto, o conteúdo encontra-se organizado na forma de hipertextos e hiperlinks, de modo a possibilitar que os materiais se intercomuniquem e o usuário possa investigar a teoria segundo a sua lógica. Aborda-se um caráter estésico através da adoção de metáforas de interface e da metodologia de "ação por descoberta" aplicada ao OA, contemplando uma exploração instigante, investigativa e surpreendente. O planejamento gráfico da página inicial do PEDESIGN reporta à arte abstrata (figura 1), utilizando símbolos além dos tradicionais, evitando qualquer condicionamento de ordem de acesso. Objetiva-se que o aluno possa se sentir instigado a investigar o material educacional digital, valorizando a sua trajetória de aprendizagem e não apenas a obtenção de um resultado final. Para apoiar ainda mais esse fim, o conteúdo é organizado em forma de desafios de modo aos alunos terem a oportunidade de realizar experimentações e refletir sobre elas, utilizando para isso significados inteligíveis e sensíveis. São 8 desafios que abordam a aplicação dos principais elementos do design pedagógico: Contextualização da imagem em materiais educacionais digitais, A Utilização da Imagem, Teoria pura e experimentação, Navegação, Ruptura, Relacionando a ruptura e as simbologias trocadas, A Utilização da Imagem, Construção de um material educacional digital, Interação e Interatividade. Também são disponibilizados materiais de apoio, como: Biblioteca, Glossário, Guia e Bibliografia.

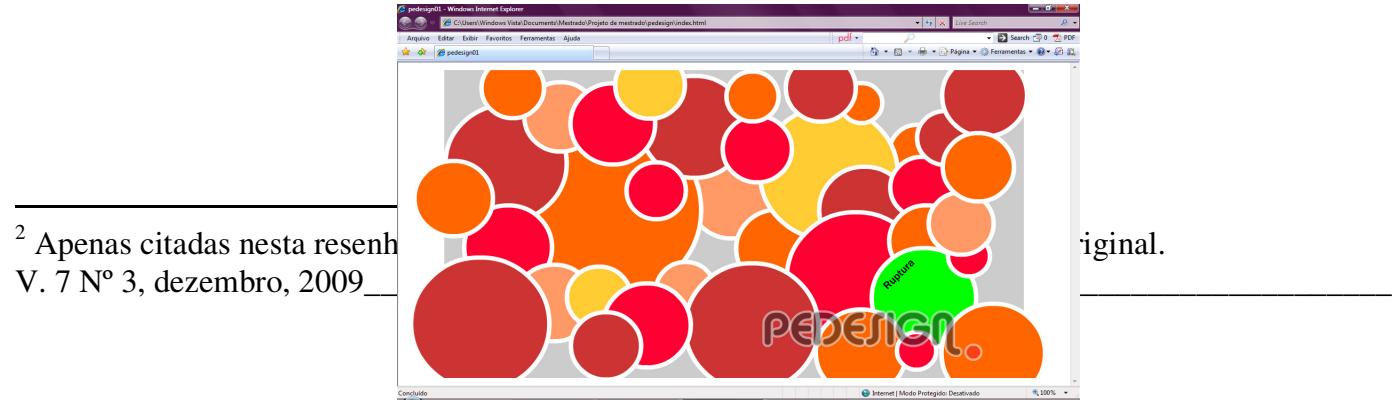

Figura 1: Tela inicial do OA PEDESIGN. 
Com o objetivo de avaliar o referido OA, assim como a validação das metas do design pedagógico, ainda nessa etapa, o OA PEDESIGN foi aplicado em dois cursos: minicurso denominado PEDESIGN ministrado no V ESUD $/ 6^{\circ}$ SENAED, em abril de 2008, realizado em Gramado; e na disciplina "Oficinas Virtuais de Aprendizagem" do curso de pós-graduação da Universidade Federal do Rio Grande do Sul (UFRGS), durante o primeiro semestre de 2008. A partir dessas práticas analisou-se tanto a relação aluno-objeto de aprendizagem, para verificar se a estrutura interativa aplicada no OA PEDESIGN contemplaria fatores ergonômicos e uma boa receptividade dentro de uma proposta diferenciada; quanto a relação aluno-objeto de estudo, com o objetivo de avaliar se a metodologia utilizada possibilitaria ou não a ação autônoma, investigativa e reflexiva do usuário sobre o conteúdo abordado.

A partir dessas aplicações foram coletados dados que posteriormente foram analisados segundo a metodologia de Roque Moraes (1999), que concebe 5 etapas: preparação das informações; unitarização ou transformação do conteúdo em unidades; categorização ou classificação das unidades em categorias; descrição; interpretação. A partir dessa análise foi possível concluir que o referido OA possibilita a ação ativa, crítica e criativa do sujeito sobre o tema de estudo. Visualiza-se ainda que ele permite que o aluno experiencie o próprio conteúdo abordado pelo MED, através de desafios que o motivam a construir possíveis soluções a situações-problema, assim como efeitos de sentido para o conteúdo estudado. Essa constatação permite não somente a comprovação de que o PEDESIGN contempla os fatores gráficos, técnicos e pedagógicos selecionados por esta pesquisa, como também que as metas do design pedagógico realmente atuam positivamente na construção de MED's que apóiam o novo perfil do usuário da geração digital. Embora a continuação desta pesquisa ou a colaboração de outros estudos nesta área possam aprimorá-los, pode-se considerar que os fatores técnicos, gráficos e pedagógicos organizados por este estudo constituem os fatores básicos responsáveis pela construção de MED's baseados no design pedagógico, de modo a apoiar a trajetória do aluno sobre o material educacional digital.

Com a validação das metas do design pedagógico, iniciou-se a terceira e conclusiva etapa deste estudo. Nela, construiu-se uma tabela de parâmetros para a elaboração de materiais educacionais digitais sob o ponto de vista do design pedagógico. A tabela foi construída de modo a contemplar um caráter reutilizável, ou seja, de modo a permitir que cada equipe desenvolvedora adeque esses parâmetros-base às necessidades do seu usuário final. Portanto, ela não aborda "um modelo a ser seguido", ao contrário, salienta pontos importantes a serem levados em conta durante o planejamento e desenvolvimento de materiais educacionais digitais sob o ponto de vista do design pedagógico. Objetiva-se, desse modo, evitar basear a construção de MED's num determinado padrão de usuário, mas possibilitar que todos padrões possam ser contemplados a partir da aplicação desta tabela de parâmetros, disposta a seguir.

Parâmetros para a construção de materiais educacionais digitais baseados no design pedagógico Parâmetros $\quad$ Metas do design pedagógico

V. $7 \mathrm{~N}^{\mathrm{o}}$ 3, dezembro, 2009 


\begin{tabular}{|c|c|c|c|}
\hline Fatores Técnicos & Metas Técnicas & Metas Gráficas & Metas Pedagógicas \\
\hline Usabilidade & $\begin{array}{l}\text { Planejar o funcionamento do } \\
\text { sistema de modo a possibilitar que } \\
\text { o usuário facilmente construa uma } \\
\text { lógica de navegação pelo MED. } \\
\text { Fornecer retorno ao usuário de } \\
\text { modo a ele saber onde está, onde } \\
\text { esteve e onde poderá estar e de que } \\
\text { maneira. } \\
\text { Possibilitar que o sistema } \\
\text { corresponda às expectativas do } \\
\text { usuário. } \\
\text { Possibilitar a resolução de uma } \\
\text { mesma tarefa através de vários } \\
\text { caminhos possíveis. } \\
\text { Elaborar estratégias de affordance } \\
\text { (fornecer pistas a respeito do } \\
\text { significado de um determinado } \\
\text { elemento de interface). } \\
\text { Controle Explícito - possibilitar ao } \\
\text { usuário o controle sobre suas ações } \\
\text { e uma eficaz comunicação usuário- } \\
\text { sistema. } \\
\text { Gestão de erros - projetar o sistema } \\
\text { de modo a ele ser capaz de } \\
\text { identificar, informar e consertar } \\
\text { possíveis erros. } \\
\text { Condução - ajudar o usuário no } \\
\text { decorrer de sua exploração pelo } \\
\text { material educacional digital. } \\
\text { Integrar os modelos conceituais } \\
\text { baseados em atividades aos } \\
\text { baseados em objetos. } \\
\text { Disponibilizar Breadcrumbs } \\
\text { ("Caminhos de Migalhas de Pão") e } \\
\text { mapa do site. }\end{array}$ & $\begin{array}{l}\text { Utilizar fatores gráficos para apoiar } \\
\text { a interpretação do funcionamento } \\
\text { do sistema pelo usuário e para } \\
\text { organizar as informações de } \\
\text { maneira legível, simples e eficiente. } \\
\text { Aplicar fatores gráficos que } \\
\text { revelem o conteúdo do site. } \\
\text { Visibilidade - estabelecer uma } \\
\text { relação lógica entre os ícones e a } \\
\text { função que desempenham. } \\
\text { Feedback - conciliar a expectativa } \\
\text { do usuário com a função dos botões } \\
\text { de navegação. } \\
\text { Mapeamento - relacionar a forma } \\
\text { dos ícones às suas funções. } \\
\text { Consistência - evitar a simples } \\
\text { digitalização do mundo real e de } \\
\text { materiais educacionais analógicos. } \\
\text { Carga de Trabalho - planejar uma } \\
\text { confortável carga de informação } \\
\text { em cada interface. }\end{array}$ & $\begin{array}{l}\text { Possibilitar controle e confiança } \\
\text { ao usuário, características } \\
\text { diretamente relacionadas com a } \\
\text { sua motivação e auto-estima. } \\
\text { Possibilitar apoio técnico para } \\
\text { que o aluno encontre liberdade } \\
\text { para zarpear pelo MED e criar } \\
\text { as suas estratégias de ação. } \\
\text { Caso haja alguma dificuldade } \\
\text { que o impeça de executar uma } \\
\text { das açôes por ele planejada, } \\
\text { esse aluno perderá a confiança } \\
\text { no sistema e se desmotivará. } \\
\text { Desistirá de agir sobre o MED } \\
\text { de maneira autônoma e } \\
\text { investigativa, se o sistema não o } \\
\text { apoiar. São os fatores } \\
\text { ergonômicos que diferenciam } \\
\text { um desafio instigante de outro } \\
\text { desmotivador. } \\
\text { extremamente relacionados com } \\
\text { o interesse, confiança e } \\
\text { motivação do usuário. O aluno } \\
\text { necessita explorar o MED sem } \\
\text { reparar nas ferramentas, mas na } \\
\text { sua trajetória em si. }\end{array}$ \\
\hline Fatores Técnicos & Metas Técnicas & Metas Gráficas & Metas Pedagógicas \\
\hline Interação e interatividade & $\begin{array}{l}\text { Planejar a implementação de } \\
\text { ferramentas que possibilitem a } \\
\text { interatividade usuário-MED. } \\
\text { Planejar a implementação de } \\
\text { ferramentas que possibilitem a } \\
\text { interação entre usuários e entre } \\
\text { usuários e professores através do } \\
\text { MED ou planejar dinâmicas que } \\
\text { possibilitem uma ação interativa/ } \\
\text { colaborativa. } \\
\text { Fornecer feedbacks aos usuários } \\
\text { (jogos educacionais e mensagens } \\
\text { do sistema). } \\
\text { Adotar uma navegação não-linear. } \\
\text { Estruturar o MED a partir da } \\
\text { adoção de modelos conceituais } \\
\text { (preferencialmente o misto). }\end{array}$ & $\begin{array}{l}\text { Utilizar fatores gráficos que apóiem } \\
\text { as açẽes e necessidades do usuário } \\
\text { ao se comunicar com outros } \\
\text { usuários ou com o sistema. } \\
\text { Expressividade - estabelecer uma } \\
\text { relação entre os símbolos utilizados } \\
\text { e o seu significado. }\end{array}$ & $\begin{array}{l}\text { Apoiar a trajetória do usuário } \\
\text { pelo MED. } \\
\text { Planejar "materiais de apoio": } \\
\text { biblioteca, guia do professor, } \\
\text { glossário, entre outros. } \\
\text { Possibilitar a ação do usuário } \\
\text { sobre o MED. } \\
\text { Permitir que o usuário interaja } \\
\text { com vários tipos de informação, } \\
\text { instigando uma relação com os } \\
\text { seus conceitos pré- } \\
\text { estabelecidos. } \\
\text { Oportunizar a interação com } \\
\text { outros usuários e professores, } \\
\text { contemplando } \\
\text { desenvolvimento de habilidades } \\
\text { sociais e colaborativas. } \\
\text { Organizar o conteúdo de modo } \\
\text { a desafiar o usuário a } \\
\text { descobertas. } \\
\text { Possibilitar a navegação por } \\
\text { livre-descoberta. } \\
\text { Fazer prevalecer a interação } \\
\text { mútua à reativa. }\end{array}$ \\
\hline
\end{tabular}




\begin{tabular}{|c|c|c|c|}
\hline Fatores Gráficos & Metas Técnicas & Metas Gráficas & Metas Pedagógicas \\
\hline Design & $\begin{array}{l}\text { Os ícones devem seguir uma lógica } \\
\text { facilmente entendível pelo usuário. } \\
\text { Alternar o grau de iconicidade } \\
\text { (baixo/médio/alto), conforme a } \\
\text { necessidade. } \\
\text { Design comportamental: planejar o } \\
\text { uso e a relação entre os elementos } \\
\text { da interface. } \\
\text { Observar os hábitos do usuário } \\
\text { final. } \\
\text { Avaliar o MED através da } \\
\text { prototipaçãa. } \\
\text { Admitir o usuário na equipe } \\
\text { desenvolvedora do MED. } \\
\text { Constante avaliação da aplicação } \\
\text { do design no MED. } \\
\text { Design centrado na ação do usuário } \\
\text { (Norman, 2006): uso de coerções, } \\
\text { tornar as "coisas" visíveis, fácil } \\
\text { avaliação do estado do sistema, } \\
\text { mapeamentos, simplificar a } \\
\text { estrutura das tarefas, adotar } \\
\text { auxiliares mneumônicos, projetar } \\
\text { para o erro. } \\
\text { O sistema deve ser projetado para } \\
\text { apoiar o comportamento do usuário } \\
\text { e o contexto. } \\
\text { Design participativo: possibilitar a } \\
\text { participação ativa do usuário no } \\
\text { sistema operacional. } \\
\text { Projetar uma relação harmônica } \\
\text { entre o mapa conceitual do sistema, } \\
\text { usuário e designer. } \\
\text { Utilizar ícones que se relacionem } \\
\text { com os signos do usuário e com a } \\
\text { composição gráfica da interface, de } \\
\text { modo a contemplar o conceito de } \\
\text { relevância. }\end{array}$ & 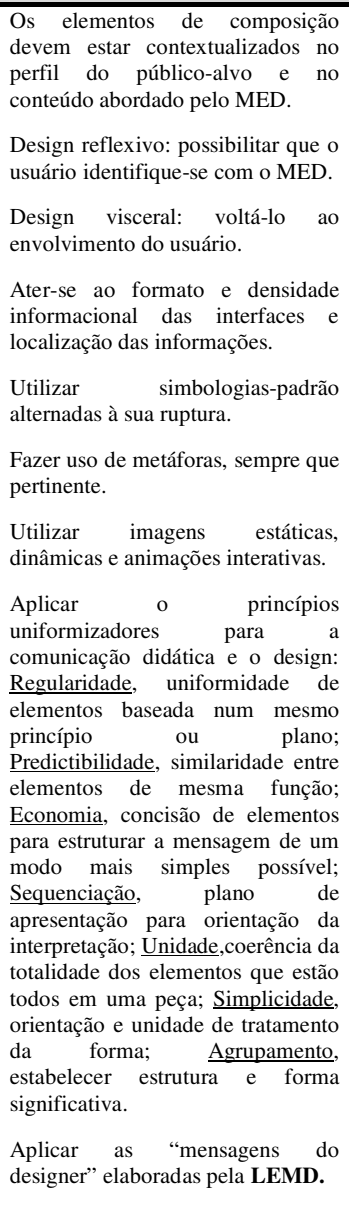 & $\begin{array}{l}\text { Os elementos de composição } \\
\text { devem ser considerados parte } \\
\text { integrante do MED e não meros } \\
\text { elementos decorativos. } \\
\text { As imagens, animações e } \\
\text { simulações devem fornecer } \\
\text { resistência à ação do usuário, } \\
\text { para que ele possa interagir com } \\
\text { conceitos prévios e novos. } \\
\text { Possibilitar que o usuário } \\
\text { identifique-se com o MED. } \\
\text { Motivação e instigação do } \\
\text { usuário: trabalhar com a ruptura } \\
\text { da simbologia padrão e a } \\
\text { contextualização das interfaces } \\
\text { na cultura do usuário e no } \\
\text { conteúdo abordado. } \\
\text { Administrar a aplicação do } \\
\text { caráter lúdico de metáforas e } \\
\text { simulações, com o objetivo do } \\
\text { aluno desprender-se da tensão } \\
\text { de aprender e valorizar a sua } \\
\text { trajetória de aprendizagem. } \\
\text { Ultrapassar os limites da } \\
\text { simples contemplação e } \\
\text { representação, de modo ao } \\
\text { observador atuar de maneira } \\
\text { crítica sobre o MED. } \\
\text { Apoiar a comunicação didática. }\end{array}$ \\
\hline Fatores Gráficos & Metas Técnicas & Metas Gráficas & Metas Pedagógicas \\
\hline Estética & $\begin{array}{l}\text { Planejar uma estética participativa: } \\
\text { diálogo entre o usuário e o MED. } \\
\text { Aplicar e relacionar as cinco } \\
\text { estéticas de Greimas (1987): } \\
\text { estética clássica, estética da graça, } \\
\text { estética da revelação, estética da } \\
\text { penetração e estética da purificação. } \\
\begin{array}{l}\text { Criar experiências r estéticas } \\
\text { apoiando-se em ratores } \\
\text { ergonômicos e nas tecnologias } \\
\text { digitais. }\end{array}\end{array}$ & $\begin{array}{l}\text { Aplicar a media art e a } \\
\text { endoestética. } \\
\text { Utilizar a arte como fator } \\
\text { sensibilizador. } \\
\begin{array}{l}\text { Não vincular a estética apenas ao } \\
\text { belo, mas, acima de tudo, à } \\
\text { experiência estética. }\end{array}\end{array}$ & 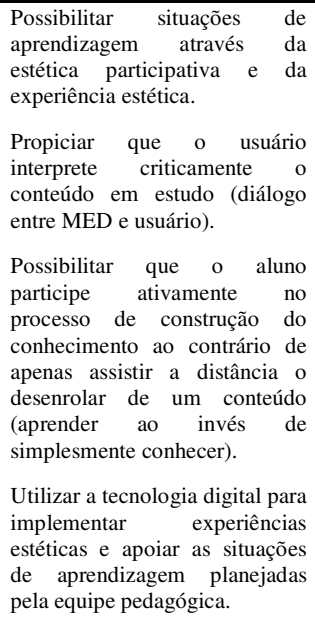 \\
\hline Fatores Gráficos & Metas Técnicas & Metas Gráficas & Metas Pedagógicas \\
\hline
\end{tabular}




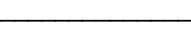

\begin{tabular}{|c|c|c|c|}
\hline Semiótica & $\begin{array}{l}\text { Aplicar a semiótica peirceana no } \\
\text { planejamento de ícones } \\
\text { relacionados a navegação e } \\
\text { usabilidade. } \\
\text { Aplicar a relação plano de conteúdo } \\
\text { x plano de expressão, da semiótica } \\
\text { greimasiana, na organização do } \\
\text { conteúdo abordado pelo MED. } \\
\text { Relação de ajuda - propiciar um } \\
\text { diálogo entre o sistema e o usuário } \\
\text { de modo ao aluno sentir-se } \\
\text { instigado pelos desafios e não } \\
\text { desestimulado. }\end{array}$ & 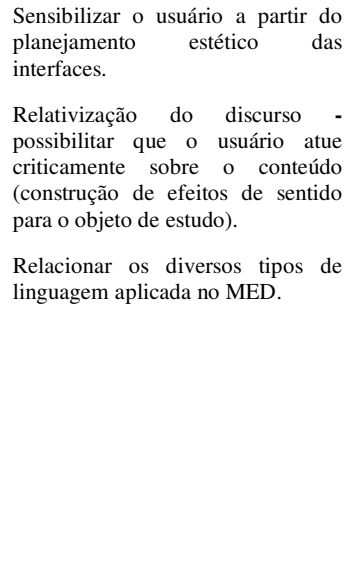 & $\begin{array}{l}\text { Romper a dessemantizada } \\
\text { rotina cotidiana, possibilitando } \\
\text { que o usuário crie efeitos de } \\
\text { sentido para o conteúdo } \\
\text { estudado. } \\
\text { Organizar o conteúdo de modo } \\
\text { a possibilitar que o usuário, ao } \\
\text { interagir com esse conteúdo, } \\
\text { elabore uma rede de relações: } \\
\text { contrariedade, } \\
\text { contraditoriedade, implicações. } \\
\text { Possibilitar que o aluno, através } \\
\text { da construção de efeitos de } \\
\text { sentido para o conteúdo, sinta- } \\
\text { se motivado a aprender. } \\
\text { Instigar o aluno a partir do } \\
\text { caráter estésico. } \\
\text { Relacionar os saberes sensível e } \\
\text { inteligível. }\end{array}$ \\
\hline
\end{tabular}

Tabela 1: Parâmetros para a construção de materiais educacionais digitais

A partir da aplicação dos fatores técnicos, gráficos e pedagógicos na construção de MED's, abordados por esta pesquisa, é possível verificar a influência do design de interface no planejamento da interatividade de materiais educacionais digitais. Ocorre que, algumas vezes, o design é interpretado como um simples ilustrador, com a função de propiciar um fino acabamento ao trabalho. Porém, ele abrange uma conceituação mais profunda, relacionada com a estrutura do material, não devendo ser visto como uma superficial cobertura, mas como parte integrante do objeto construído. Verifica-se a responsabilidade de educadores, professores, alunos e designers na elaboração de materiais educacionais digitais e a necessidade da formação de uma equipe interdisciplinar. Isso porque a prática pedagógica não deve ser pensada apenas na etapa de docência, mas concebida na origem da elaboração do material educacional digital, possibilitando uma interação entre fatores técnicos, gráficos e pedagógicos, de modo a um fornecer apoio e suporte ao outro. É com esse objetivo que esta pesquisa propõe a construção do conceito de design pedagógico, admitindo-o como aquele responsável por relacionar fatores técnicos, gráficos e pedagógicos durante a elaboração de materiais educacionais digitais. Objetiva-se, assim, incentivar a reflexão e conscientização de professores, pedagogos e designers sobre o papel do design pedagógico na construção de materiais educacionais digitais.

\section{Referências:}

AMANTE, Lúcia; MORGADO, Lina. Metodologia de concepção e desenvolvimento de aplicações educativas: o caso dos materiais hipermedia. In: Discursos, III Série, $\mathrm{n}^{\mathrm{o}}$ especial, pp.125-138, Universidade Aberta, 2001.

GREIMAS, Algirdas Julien (1987). De l'imperfection. Périgueux: Pierre Fanlac, 1987.

MORAES, Roque. Análise de Conteúdo. Educação. V. 22, n.37. Porto Alegre: EDIPUCRS, 1999, p.7-31.

NORMAN, Donald A. O Design Do Dia-A-Dia. Rio de Janeiro: Ed. ROCCO, 2006.

ROMISZOWSKI, Alexander; ROMISZOWSKI, Lina. Retrospectiva e Perspectivas do Design

Instrucional e Educação a Distância: análise da literatura. Revista Brasileira de Aprendizagem Aberta e a Distância. v. 3, n. 1, 2005. Disponível em: <http://www.abed.org.br>. Acesso em: 28/11/2009. 